\title{
Prenatal Diagnosis of Cephalophagus Conjoined Twins by Ultrasonography and Magnetic Resonance Imaging
}

\author{
Ravi Kapoor ${ }^{1}$ Ashutosh Bansal ${ }^{1}$ Abhinav Aggarwal $^{2,4}$. \\ Aakriti Kapoor Aggarwal ${ }^{2} \cdot$ Radhika Batra Taneja $^{3}$
}

Received: 4 March 2015/ Accepted: 20 May 2015/Published online: 26 June 2015

(C) Society of Fetal Medicine 2015

\begin{abstract}
Cephalopagus is the rarest type of conjoined twins. Early antenatal diagnosis is important in view of extremely poor prognosis as surgical separation is not possible in such cases. Fetal MRI is an excellent complementary tool to prenatal sonography in assessment of complex fetal anomalies.
\end{abstract}

Keywords Conjoined twins · Cephalopagus · Prenatal diagnosis · Fetal MRI · Prenatal ultrasonography

\section{Introduction}

Although exact prevalence is unknown, conjoined twins are rare with estimated prevalence in the literature varying widely, from 1:50,000 to 1:200,000 [1,2]. All types of conjoined twins are monozygotic, monochorionic and are thought to result from failure of separation of the embryonic plate between 13 and 17 days gestation [3].

The classification of conjoined twins is according to the most prominent site of connection: the thorax (thoracopagus), abdomen (omphalopagus), sacrum (pyopagus), pelvis (ischiopagus), skull (craniopagus), face (cephalopagus), or back (rachipagus) [4]. Cephalopagus type of conjoined twins are teratodelphic, and united high in the body in the form of a lamda

Abhinav Aggarwal

abhinavagg@gmail.com

City X-ray and Scan Clinic, Vikas Puri, New Delhi, India

2 Shri Ram Murti Smarak Institute of Medical Sciences, Bareilly, Uttar Pradesh, India

3 City X-ray and Scan Clinic, Tilak Nagar, New Delhi, India

4 A-1/237, First Floor, Janak Puri, New Delhi 110058, India
[5]. Cephalopagus twinning, the rarest type of conjoined twins, is characterized by anterior union of the upper half of the body including the head [6]. Of conjoined twins, $40 \%-60 \%$ are stillborn, and almost $35 \%$ of live births do not survive after $24 \mathrm{~h}$ with better prognosis achieved if surgery is done at least three weeks after birth [7]. The prognosis for cephalopagus conjoined twins is poor and dependent on the associated anomalies present and the degree of fusion of the intracranial, intrathoracic, and intra-abdominal structures. Early and accurate prenatal diagnosis of cephalopagus twins enables parents to opt for early pregnancy termination, thus reducing the risk of trauma to the birth canal via vaginal delivery in such cases. Ultrasonography and magnetic resonance imaging (MRI) are excellent noninvasive techniques that aid in the diagnosis and management of such cases. 3D/4D ultrasound imaging can provide exquisite and anatomical details regarding the site and extent of fusion. Fetal MRI and ultrasonography can be used as complementary techniques and the detailed anatomical information facilitates counseling of the family and neonatal surgical planning, wherever possible.

Here we present a rare case of conjoined twins with cephalopagus twinning, where a fused upper abdomen and chest with a single head was seen.

\section{Report of Case}

A 30-year-old healthy woman, gravida 1 was referred for an antenatal ultrasound. She had regular menstrual cycles with no family history of consanguinity or twinning in the family. She was an unbooked case with no previous antenatal records and felt larger for gestational age.

Prenatal sonographic images showed a conjoined twins with a single fetal head, fused thoraces, two separate vertebral columns and separate pelvises with one heart, a shared liver, 
four kidneys and two urinary bladders (Fig. 1a, b). Four upper and four lower extremities were observed (Fig. 2a, b). The gestational age was approximately 21 weeks. A single placenta and single cord with more than three vessels were noted. Subsequent 3D sonography provided excellent details regarding the extent of fusion (Fig. 3). A fetal MRI done subsequently revealed a single head with two optic globes, two cerebral hemispheres with a normal posterior fossa having a cerebellum with two hemispheres. Two spinal canals were seen to enter the base of skull (Figs. 4-6). No evidence of ventricular dilatation was noted. The presence of a single heart, a pair of lungs, shared liver, four kidneys, and two bladders was confirmed.

The parents were explained about the poor prognosis and opted for termination. They were referred to an appropriate center. A cephalopagus fetus with multiple anomalies was delivered vaginally. A single head and face was seen with two eyes, two ears, single nose, and mouth with a protruding tongue. No cleft-palate/-lip was seen. No obvious other facial structures/skin tags were identified on the other side of the head (Fig. 7).

\section{Discussion}

An increased prevalence of conjoined twins is observed in parts of Southeast Asia and Africa, with reported occurrence ranging from $1: 14,000$ to $1: 25,000[1,2]$. No significant genetic, environmental, or demographic-associated factors have been identified but there is a female predominance of the order of 3:1 [8].

The embryonic classification of conjoined twins consists of ventral union $(87 \%)$ and dorsal union $(13 \%)$. There are altogether eight types of conjoined twins that vary as to the extent and location of their union [9]. The most common types of conjunction: thoracopagus, omphalopagus, and thoraco-ompalopagus account for $56 \%$ of conjoined twins. The cephalopagus is the rarest type among the ventral union subgroup of conjoined twins and accounts for $11 \%$ of all cases, i.e., one per million births [10]. It consists of a ventral union of the upper half of the body from top of head to upper abdomen. This could either be the Janiceps (Greek god with two faces) type with two faces on either side of the head or non Janiceps type with relatively normal one head with a small otocephalic face on the other side [9]. The type of cephalophagus, which we encountered, is the non Janiceps type but in the present case no facial structures were identified on the other side of the head unlike those discussed in literature.

The heart and liver are often conjoined, but the lower abdomen and pelvis are separate. There are four arms and four legs. The prognosis is extremely poor as surgical separation of such twins is not an option [6]. Cephalopagus twins may be mistaken for a singleton fetus because of their extreme degree of fusion. Therefore, early prenatal diagnosis of cephalopagus by ultrasonography and MRI is
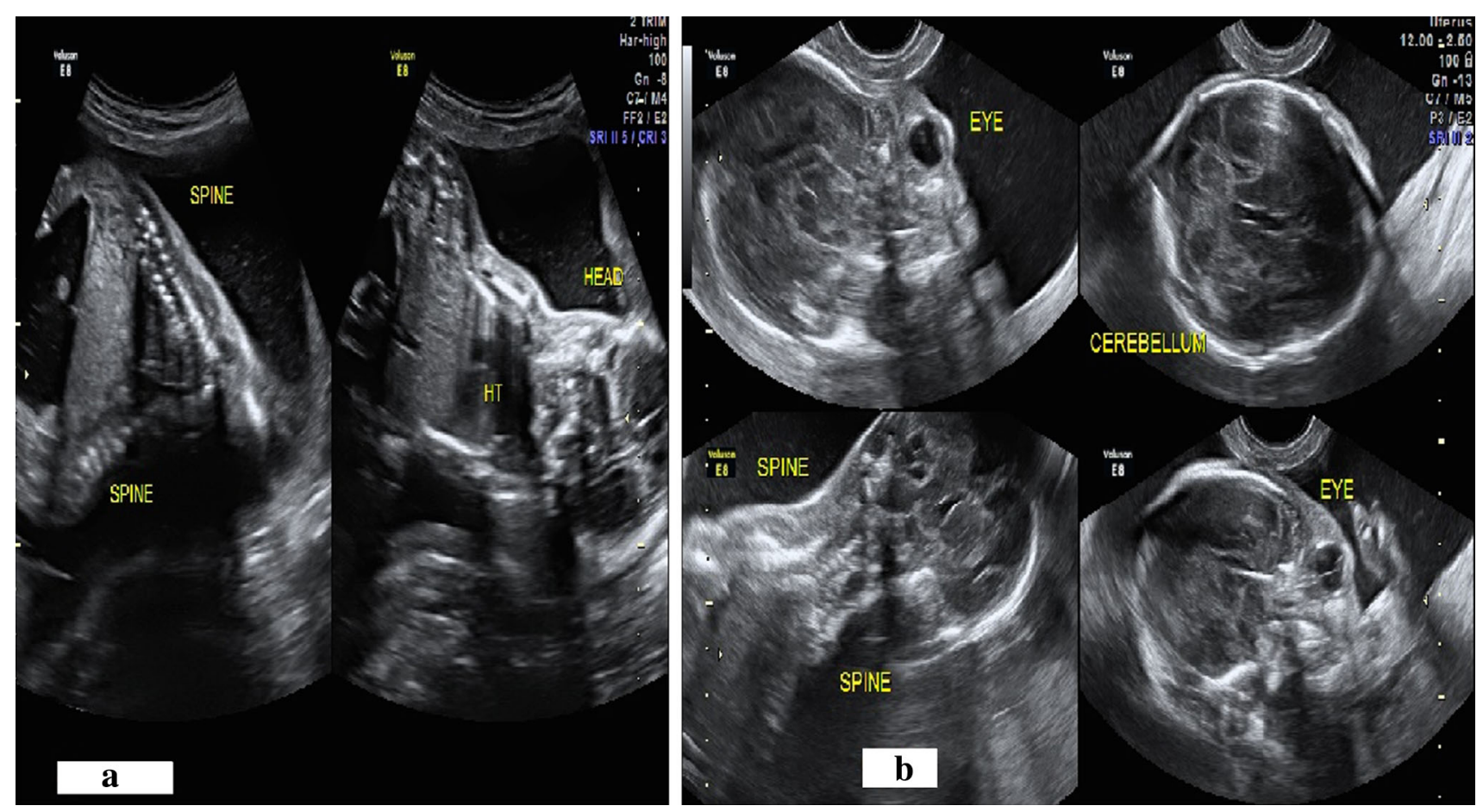

Fig. 1 a Longitudinal image of the twin fetuses showing two vertebral columns with fused thorax with a single heart b Transverse and longitudinal images revealing two vertebral columns connected to a single head 

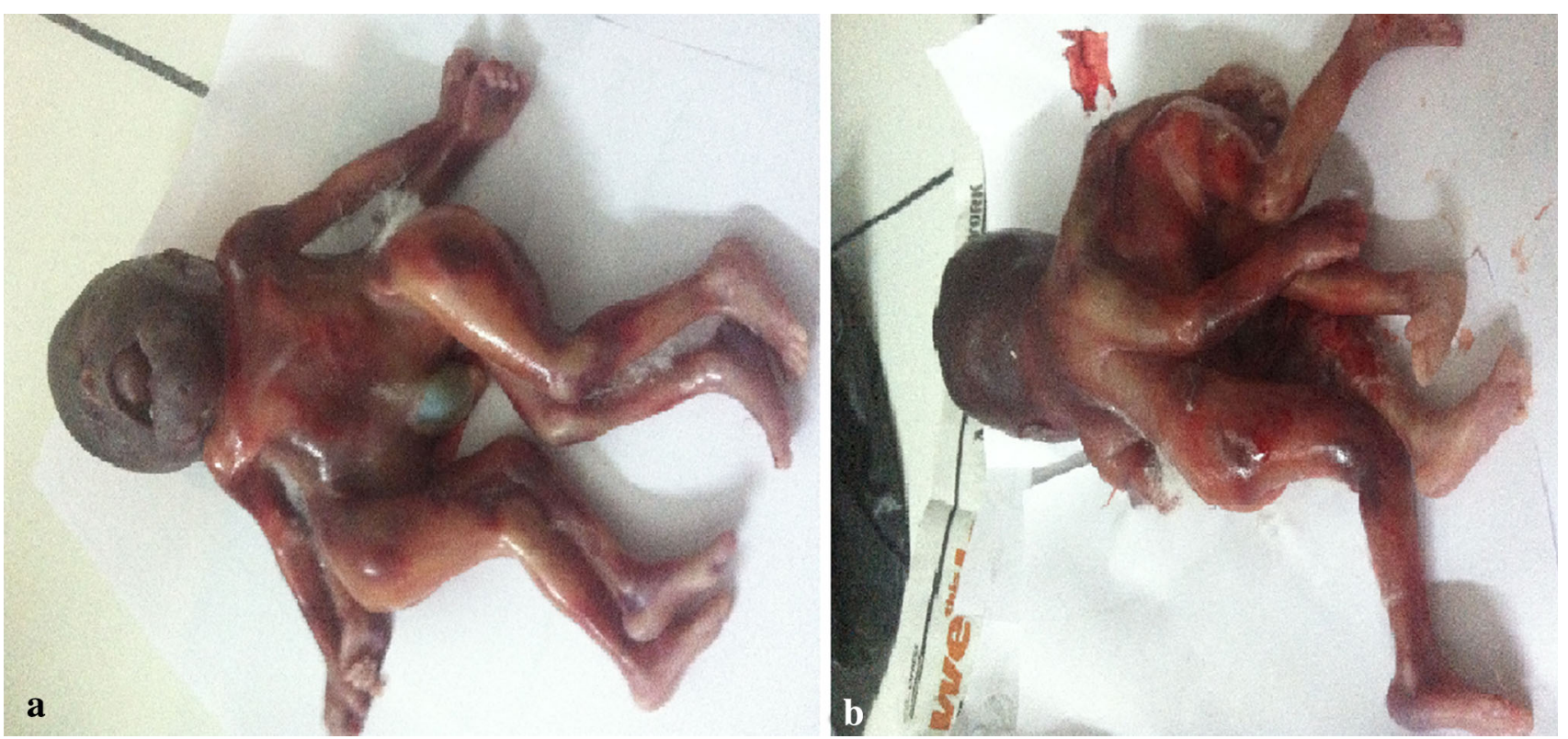

Fig. 2 a Photograph of the delivered fetus showing a single abnormal large head with fused thoraces and upper abdomens; four upper and four lower extremities b Photograph showing absence of the face on the other side of the head

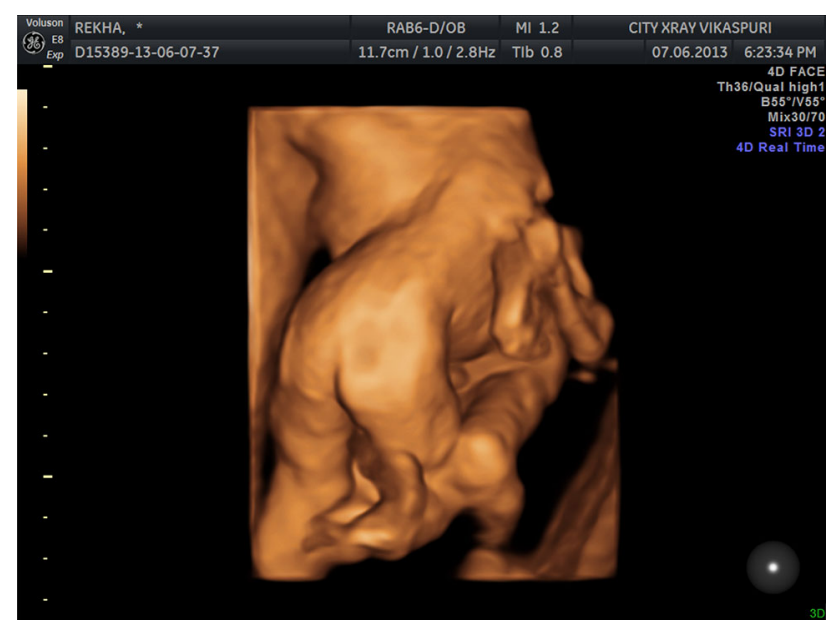

Fig. 3 3D ultrasound image demonstrating fusion of the twins in the region of the thorax and upper abdomen, and four lower extremities

extremely important. Timely obstetric management helps in minimizing maternal and fetal morbidity and mortality.

If the diagnosis is made before viability, termination of the pregnancy by vaginal delivery may be possible. Later in pregnancy, the decision regarding vaginal delivery versus cesarean section is based on the size of fetuses and the likelihood of survival.

Antenatal ultrasound is capable of diagnosing a conjoined twin pregnancy as early as 12 weeks gestation. Transvaginal ultrasound may also aid early diagnosis. The possibility of conjoined twins should be suspected in a twin pregnancy with a single placenta and no visible separating amniotic membrane. The observation of two placentas or an amniotic membrane excludes conjoining. The ultrasound findings include inseparable fetal bodies, unvarying relative positioning of the two fetuses, both heads persistently at the same level to each other, bi-breech or bicephalic presentations and a single umbilical cord with more than three vessels. Most conjoined twins face each other and are fused ventrally, resulting in hyperextension of their cervical spines. Polyhydramnios complicates up to $50 \%$ of conjoined twin pregnancies, compared to about $10 \%$ of normal twin pregnancies. Detailed ultrasound assessment at around 20 weeks gestation can define the site and extent of the conjoined area. The role of 3D ultrasound imaging has been emphasized to demonstrate the extent of fusion in conjoined twins and thus improve the accuracy of classification of conjoined twins [11].

Ultrasonography in the present case demonstrated two vertebral columns connected to a single head, single fourchambered heart and shared liver with four kidneys and two urinary bladders. Single umbilical cord with multiple vessels and single placenta were seen. Amniotic fluid index was increased. 3D sonography images revealed conjoined twins with fusion of the thoracic cavity and upper abdomen with multiple limbs.

Evaluation of complex congenital abnormalities in utero is challenging, and combined imaging with ultrasound and MRI has been shown to be helpful. Although the advantages of ultrasound include real-time scanning, color and Doppler flow, easy accessibility, and safety, MRI can 

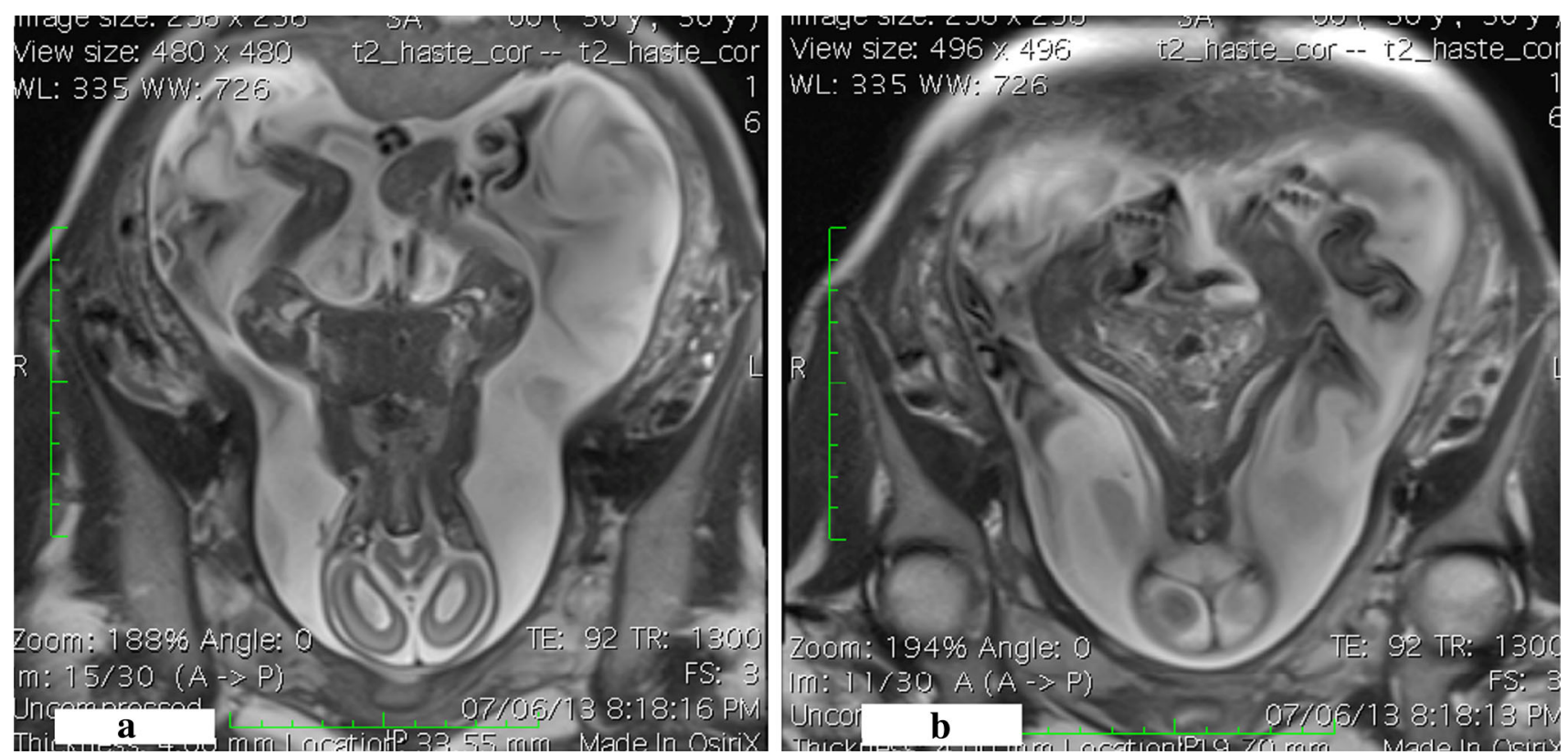

Fig. 4 Coronal T2W. a MRI showing two cerebral hemispheres, a pair of lungs, single heart, shared liver with two pelvises and two urinary bladders, b HASTE image revealing two spinal cords connected to a single head

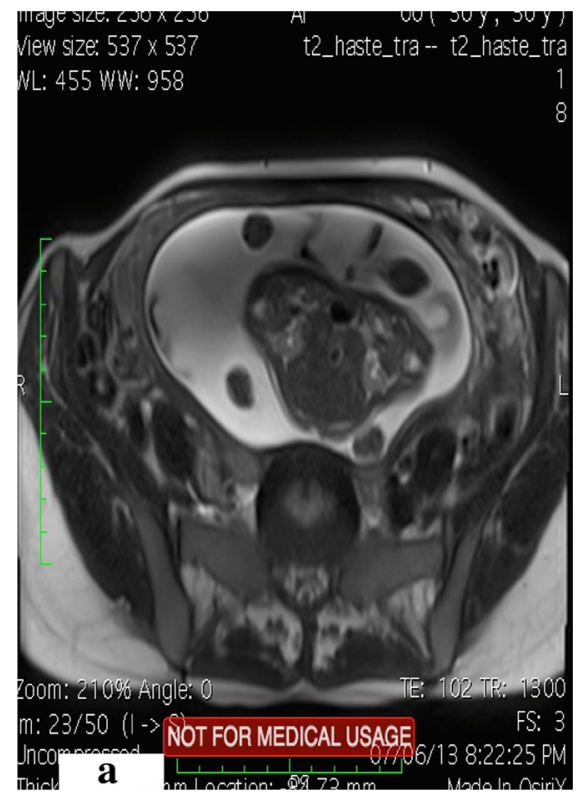

Fig. 5 Axial. a HASTE MRI showing four kidneys with a fused liver in the cephalopagus conjoined twins, b T2W image demonstrating two eyeballs and two spinal cords in the cervical region, $\mathbf{c}$ Fusion of

provide excellent detail, increased tissue contrast, and reproducible fetal anatomy. MRI is a safe and nonionizing imaging technique that has no known deleterious effects on fetuses [6]. Newer rapid image acquisition (HASTE or SSFSE) sequences yield short imaging time, good resolution and high $\mathrm{T} 2$ weighted contrast. The anatomic detail achieved with the SSFSE sequence allows much greater

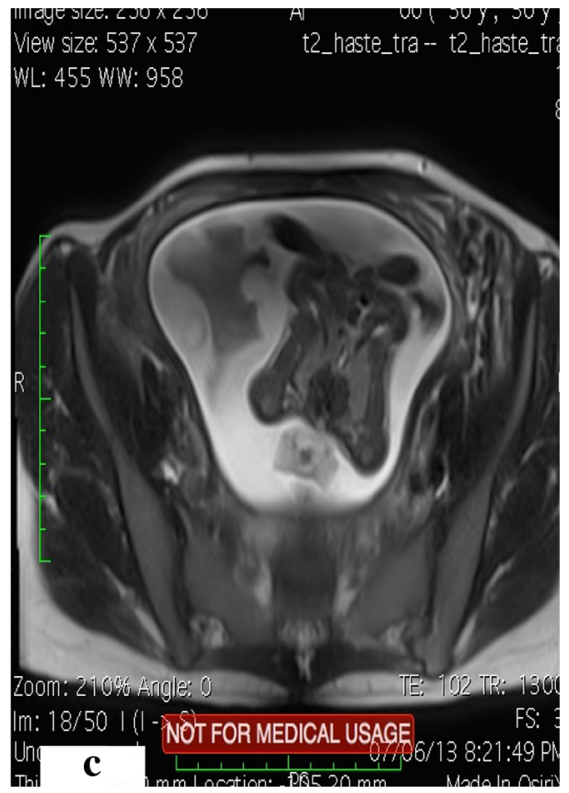

the thoracic cavities with a pair of lungs and a single heart evident in T2W HASTE image

characterization of the degree of fetal anomalies and shared organs. Minimal image degradation by fetal motion is seen and high-quality images of fetal organs can be obtained obviating the need for fetal or maternal sedation. The larger field of view of MRI permits better evaluation of the spatial relationships of anatomical anomalies or between normal structures $[12,13]$. 


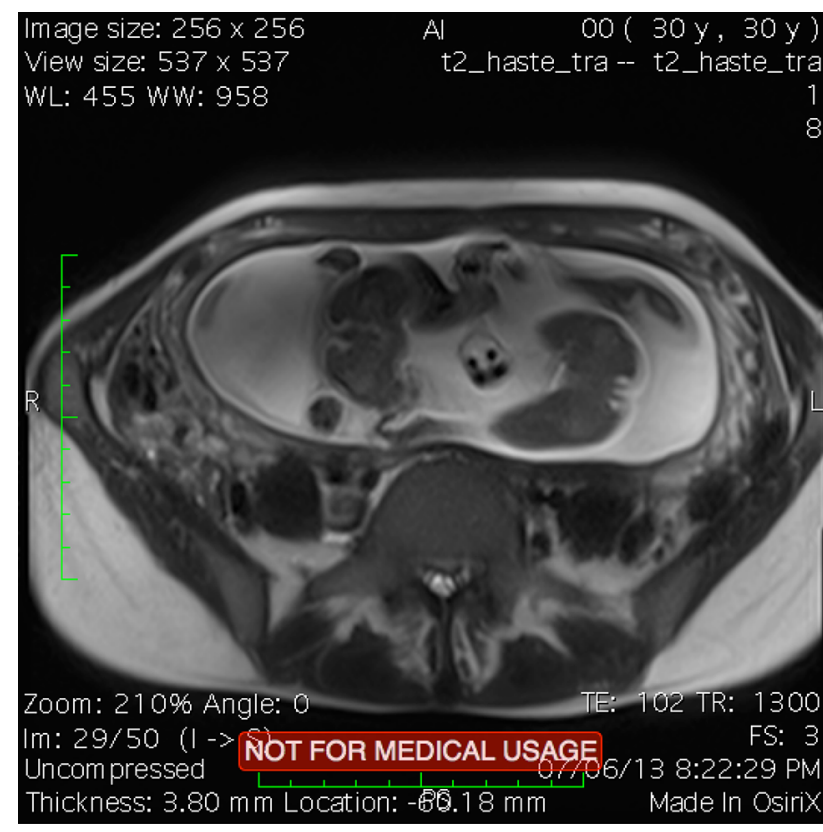

Fig. 6 Axial T2W image revealing the presence of two unfused pelvic cavities with four lower extremities and a single umbilical cord

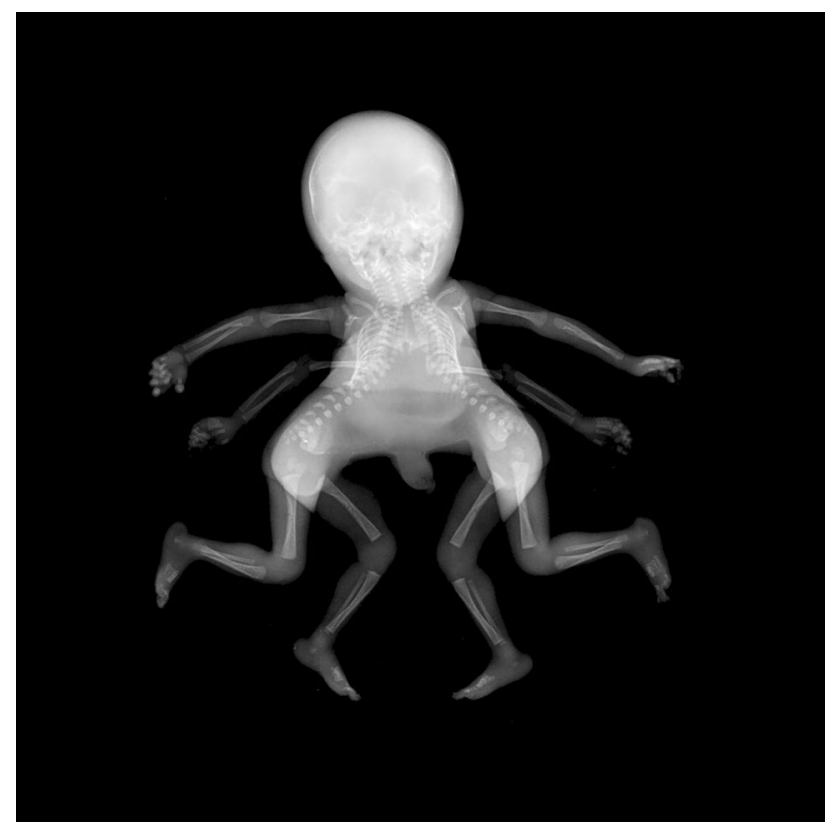

Fig. 7 Postmortem radiographs of the cephalopagus twins showing a single skull, fused thorax with two vertebral columns, two pelvises, four upper, and four lower extremities

Quinn et al. used fetal MRI for evaluation of fetuses with congenital diaphragmatic hernias for liver herniation into the chest and to differentiate between cystic adenomatoid malformations and bronchopulmonary sequestration [14]. Fetal MRI is extremely useful in evaluation of central nervous system abnormalities, especially in cases where ultrasound evaluation is limited. It yields excellent contrast between cerebrospinal fluid, brain, and spinal cord [12].

In the present case, fetal MRI increased the accuracy of diagnosis and classification of cephalopagus type of conjoined twins. Two spinal cords connected to a single head were well visualized. Two cerebral and cerebellar hemispheres were seen without ventricular dilatation. The neck, thoracic cavity, and upper abdomen were fused with a single heart and shared liver seen centrally. Two pelvises were seen with two kidneys and a bladder in each pelvis. The MRI also confirmed the presence of four upper and four lower extremities. Liquor appeared to be increased for gestational age. MRI also, due to its better visual comprehension of gross deformity, helped in counseling of the family and helped in explaining the deformities better to the parents.

In conclusion, both ultrasound and MRI are excellent complementary tools for early diagnosis, better evaluation, and classification of conjoined twins. To the best of our knowledge, no such case has been reported yet, wherein, a case of cephalopagus twin, a normal single head with two spinal canals were seen to enter the single skull and no obvious otocephalic head/skin tag representing the other cranium could be seen both prenatally or postdelivery of conceptus.

Conflict of Interest The authors declare that they have no conflict of interest.

\section{References}

1. Hanson JW. Incidence of conjoined twinning (letter). Lancet. 1975;2:1257.

2. Spitz L. Conjoined twins. Br J Surg. 1996;83:1028-30.

3. Zimmermann AA. Embryological and anatomical considerations of conjoined twins. Birth Defects. 1967;3:18-27.

4. Kingston CA, Mchugh K, Kumaradevan J, et al. Imaging in the preoperative assessment of conjoined twins. Radiographics. 2001;21(5):1187-208.

5. Cuillier F, Dillon KC, Scemama JM, Gervais T. History, classification and two cases of conjoined twins. http://sonoworld.com/ fetus/page. aspx?id=2017. Accessed Mar 2015.

6. Ozkur A, Karaca M, Gocmen A, Bayram M, Sirikci A. Cephalopagus conjoined twins presented with encphalocele: diagnostic role of ultrafast MR imaging. Diagn Interv Radiol. 2006;12:90-2.

7. Entezami M, Albig M, Knoll U, et al. Ultrasound diagnosis of fetal anomalies. Stuttgart: Thieme; 2003.

8. Gore RM, Filly RA, Parer JT. Sonographic antepartum diagnosis of conjoined twins. Its impact on obstetric management. JAMA. 1982;247(24):3351-3.

9. Sabih D, Ahmad E, Sabih A, Sabih Q. Ultrasound diagnosis of cephalopagus conjoined twin pregnancy at 29 weeks. Biomed Imaging Interv J. 2010;6(4):e38.

10. Slager VT, Anderson VM, Handmaker SD. Cephalothoracopagus janiceps malformation: a contribution to the pathogenesis of cerebral malformation. Arch Neurol. 1981;38:103-8. 
11. Basgul A, Kavak ZN, Sezen D, et al. Thoraco-omphalopagus conjoined twins detected at as early as 9 weeks of gestation: transvaginal two-dimensional ultrasound, color Doppler and fetoplacental Doppler velocity waveform findings. Fetal Diagn Ther. 2006;21(5):477-80.

12. Shakuda M, Tnooe Y, Machizuki K, Manobe T, Muna R, Oda J, Yamada R. Fast MR imaging and ultrafast imaging of fetal central nervous system abnormalities. Osaka City Med J. 2001;47:127-35.

13. Casele HI, Meyer JR. Ultrafast Magnetic resonance imaging of cephalopagus conjoined twins. Obstet Gynecol. 2000;95:1015-7.

14. Quinn TM, Hubbart AM, Adzick NS. Prenatal magnetic resonance imaging enhance fetal diagnosis. J Pediatr Surg. 1998;33:553-8. 